\title{
Determinants of improvement in six-minute walk distance from admission to discharge in acute systolic heart failure: Analysis from the ESCAPE trial
}

\author{
Hesham R. Omar ${ }^{1}$, Maya Guglin ${ }^{2}$ \\ ${ }^{1}$ Internal Medicine Department, Mercy Medical Center, Clinton, Iowa, United States \\ ${ }^{2}$ Division of Cardiovascular Medicine, Linda and Jack Gill Heart Institute, University of Kentucky, \\ Lexington, KY, United States
}

The 6-minute walk test (6MWT) is a simple, feasible test reflective of daily life activity in patients with chronic heart failure (HF) and has been used as a measure of functional status [1]. The 6MWT is also valuable to assess response to therapeutic intervention in patients with moderate to severe HF [2]. Prior studies demonstrated that the change in the 6 -minute walk distance (6MWD) from admission-to-discharge was an independent predictor of survival [3] and worsening HF requiring rehospitalizaiton [4]. The prognostic effect of $6 \mathrm{MWT}$ in $\mathrm{HF}$ was the basis for its use as a primary endpoint in clinical trials. The aim of this study is to identify determinants of improvement in 6MWD from admission to discharge, and to determine whether the degree of decongesting patients with acute systolic $\mathrm{HF}$ with diuretics was a predictor of improvement in walking distance.

The ESCAPE trial randomized 433 patients with acute $\mathrm{HF}$ with ejection fraction $(\mathrm{EF}) \leq 30 \%$ to either clinical assessment alone versus clinical assessment guided by pulmonary artery catheterization (PAC). The study showed that the PAC did not improve or worsen HF outcomes [5, 6]. 6MWD was measured in feet, and assessed at multiple time points including admission and discharge. The degree of decongestion was examined through clinical, laboratory, echocardiographic and PAC variables (Table 1). Continuous variables were expressed as median and interquartile range, and were reported as counts and percentages and compared using Mann-Whitney test and categorical variables were compared using $\chi^{2}$. Longitudi- nal comparison of the 6MWD on admission and discharge was performed using paired sample T-test. The association between the improvement in 6MWD and a selection of variables was examined using Spearman's correlation. A multivariable regression model was performed to identify independent predictors of improvement in 6MWD.

Two hundred twenty two patients (mean age 55 years, $78 \%$ men) had recorded measurements for 6MWD on admission and discharge. After $7.9 \pm 5.6$ days, the distance walked increased from $601 \pm 375$ feet to $806 \pm 390$ feet $(p<0.001)$. The average improvement in 6MWD from admissionto-discharge was 205 feet (median: 160 feet; $49 \mathrm{~m}$ ). 110 patients had an improvement in 6MWD $>160$ feet and 112 experienced an improvement in $6 \mathrm{MWD} \leq 160$ feet. Compared with patients with improvement in $6 \mathrm{MWD} \leq 160$ feet, those with improvement in 6MWD > 160 feet were younger $(\mathrm{p}=0.009)$, with a lower $6 \mathrm{MWD}$ on admission $(\mathrm{p}<0.001)$, lower frequency of atrial fibrillation $(\mathrm{p}=0.036)$, lower frequency of aortic stenosis $(\mathrm{p}=0.007)$ and a trend towards lower frequency of angina pectoris $(\mathrm{p}=0.088)$. No difference was found between the groups with regard to the degree of decongestion or improvement in cardiac output from admission-to-discharge (Table 1). There were also no significant differences between the groups in baseline left and right ventricular EF.

Correlation analysis in the whole cohort (222 cases) showed that the improvement in 6MWD was inversely correlated with patients' age ( $\mathrm{n}=222$, $\mathrm{r}=-0.179, \mathrm{p}=0.008)$ and baseline $6 \mathrm{MWD}$

Address for correspondence: Hesham R. Omar, MD, Internal Medicine Department, Mercy Medical Center, Clinton, Iowa, USA, tel: 312-714-9272, e-mail: hesham.omar@apogeephysicians.com 
Table 1. Comparison of clinical, echocardiographic and hemodynamic characteristics of ESCAPE trial patients according to whether improvement in 6-minute walk distance (6MWD) from admission-to-discharge was $>$ or $\leq 160$ feet $(49 \mathrm{~m})$.

\begin{tabular}{|c|c|c|c|}
\hline & $\begin{array}{l}\text { 6MWD improvement } \\
>160 \text { feet }(n=110)\end{array}$ & $\begin{array}{l}\text { 6MWD improvement } \\
\leq 160 \text { feet }(n=112)\end{array}$ & $\mathbf{P}$ \\
\hline \multicolumn{4}{|l|}{ Baseline demographics } \\
\hline Age [years], median (IQR] & $53.5(42,61.5)$ & $58(48,68)$ & 0.009 \\
\hline Male sex & $79.1 \%(87 / 110)$ & $76.8 \%(86 / 112)$ & 0.679 \\
\hline White race & $50.9 \%(56 / 110)$ & $65.2 \%(73 / 112)$ & 0.031 \\
\hline Black race & $29.1 \%(32 / 110)$ & $19.6 \%(22 / 112)$ & 0.101 \\
\hline Baseline 6MWD [feet], median (IQR) & $487(245,681)$ & $706(369,993)$ & $<0.001$ \\
\hline Baseline 6MWD [m], median (IQR) & $148(75,208)$ & $215(112,303)$ & $<0.001$ \\
\hline \multicolumn{4}{|l|}{ Comorbidities } \\
\hline Ischemic etiology of HF & $41.8 \%(46 / 110)$ & $52.3 \%(58 / 111)$ & 0.120 \\
\hline Atrial fibrillation & $20 \%(22 / 110)$ & $32.4 \%(36 / 111)$ & 0.036 \\
\hline Angina pectoris & $25.5 \%(28 / 110)$ & $36 \%(40 / 111)$ & 0.088 \\
\hline Coronary artery bypass graft & $26.4 \%(29 / 110)$ & $30.6 \%(34 / 111)$ & 0.482 \\
\hline Chronic obstructive pulmonary disease & $15.5 \%(17 / 110)$ & $16.2 \%(18 / 111)$ & 0.877 \\
\hline Mitral regurge & $9.1 \%(10 / 110)$ & $12.6 \%(14 / 111)$ & 0.400 \\
\hline Aortic stenosis & $0 \%(0 / 110)$ & $6.3 \%(7 / 111)$ & 0.007 \\
\hline Stroke & $8.2 \%(9 / 110)$ & $8.1 \%(9 / 111)$ & 0.984 \\
\hline Malignancy & $3.6 \%(4 / 110)$ & $7.2 \%(8 / 111)$ & 0.241 \\
\hline Depression & $19.1 \%(21 / 110)$ & $13.5 \%(15 / 111)$ & 0.262 \\
\hline \multicolumn{4}{|l|}{ Clinical variables of decongestion } \\
\hline Reduction in 6MWD [feet], median (IQR) & $356(254,574)$ & $35(-80,105)$ & - \\
\hline Weight loss [kg], median (IQR) & $2.5(0.91,4.99)$ & $2.5(0.9,5.54)$ & 0.633 \\
\hline Resolution of JVD on discharge & $62 \%(62 / 100)$ & $64.7 \%(66 / 102)$ & 0.204 \\
\hline Resolution of orthopnea on discharge & $57.1 \%(60 / 105)$ & $49.5 \%(49 / 99)$ & 0.274 \\
\hline Resolution of HJR on discharge & $70.1 \%(61 / 87)$ & $57.6 \%(57 / 99)$ & 0.076 \\
\hline \multicolumn{4}{|l|}{ Laboratory variables of decongestion } \\
\hline BNP reduction $[\mathrm{pg} / \mathrm{mL}]$, median (IQR) & $63(-51,327)$ & $163(27,520)$ & 0.058 \\
\hline \multicolumn{4}{|l|}{ PAC variables of decongestion } \\
\hline RAP change [mm Hg], median (IQR) & $-3(-8,0)$ & $-2(-5.5,2)$ & 0.408 \\
\hline PCWP change [mm Hg], median (IQR) & $-7(-15,-3)$ & $-6(-13,-1)$ & 0.347 \\
\hline PASP change [mm Hg], median (IQR) & $-11.5(-21.5,0)$ & $-9(-18.8,-2.25)$ & 0.792 \\
\hline PADP change [mm Hg], median (IQR) & $-7(-13,-1.75)$ & $-5.5(-13,0)$ & 0.665 \\
\hline $\mathrm{Cl}$ change $\left[\mathrm{L} / \mathrm{min} / \mathrm{m}^{2}\right]$, median (IQR) & $0.4(-0.08,0.7)$ & $0.38(-0.09,0.79)$ & 0.962 \\
\hline CO change [L/min], median (IQR) & $0.7(-0.2,1.4)$ & $0.8(-0.19,1.28)$ & 0.964 \\
\hline \multicolumn{4}{|l|}{ Echocardiographic variables of decongestion } \\
\hline IVC inspiration change [cm], median (IQR) & $-0.41(-0.79,0.12)$ & $-0.21(-0.77,0.19)$ & 0.366 \\
\hline IVC expiration change [cm], median (IQR) & $-0.4(-0.88,0.09)$ & $-0.18(-0.45,0.21)$ & 0.126 \\
\hline IVC collapsibility index change [cm], median (IQR) & $3.91(-3.98,19.86)$ & $1.85(-8.87,16.54)$ & 0.574 \\
\hline Left ventricular EF [\%], median (IQR)* & $19.4(11,26.7)$ & $17.6(12.6,23.3)$ & 0.777 \\
\hline Right ventricular EF [\%], median (IQR)* & $22(12.7,30.8)$ & $24.3(18.1,29.1)$ & 0.823 \\
\hline
\end{tabular}

These echocardiographic variables were recorded at baseline; HF — heart failure; JVD — jugular venous distension; HJR — hepatojugular reflux, BNP - B-type natriuretic peptide; PAC — pulmonary artery catherization; RAP — right atrial pressure; PCWP - pulmonary capillary wedge pressure; PASP — pulmonary artery systolic pressure; PADP — pulmonary artery diastolic pressure; $\mathrm{Cl}$ — cardiac index; CO — cardiac output; IVC — inferior vena cava; EF — ejection fraction; IQR — interquartile range

( $\mathrm{n}=222, \mathrm{r}=-0.358, \mathrm{p}<0.001)$. Nonetheless, no association was found between admissionto-discharge improvement in 6MWD and admission-to-discharge weight loss $(\mathrm{p}=0.701)$, admission-to-discharge reduction in right atrial pressure $(\mathrm{p}=0.502)$, admission-to-discharge reduction in pulmonary capillary wedge pressure $(\mathrm{p}=0.370)$, admission-to-discharge reduction in inferior vena cava diameter during inspiration $(\mathrm{p}=0.807)$ and expiration $(\mathrm{p}=0.386)$, and admission-to-discharge reduction in B-type natriuretic peptide (BNP; $p=0.081$ ) (Fig. 1). Multivariable lin- 


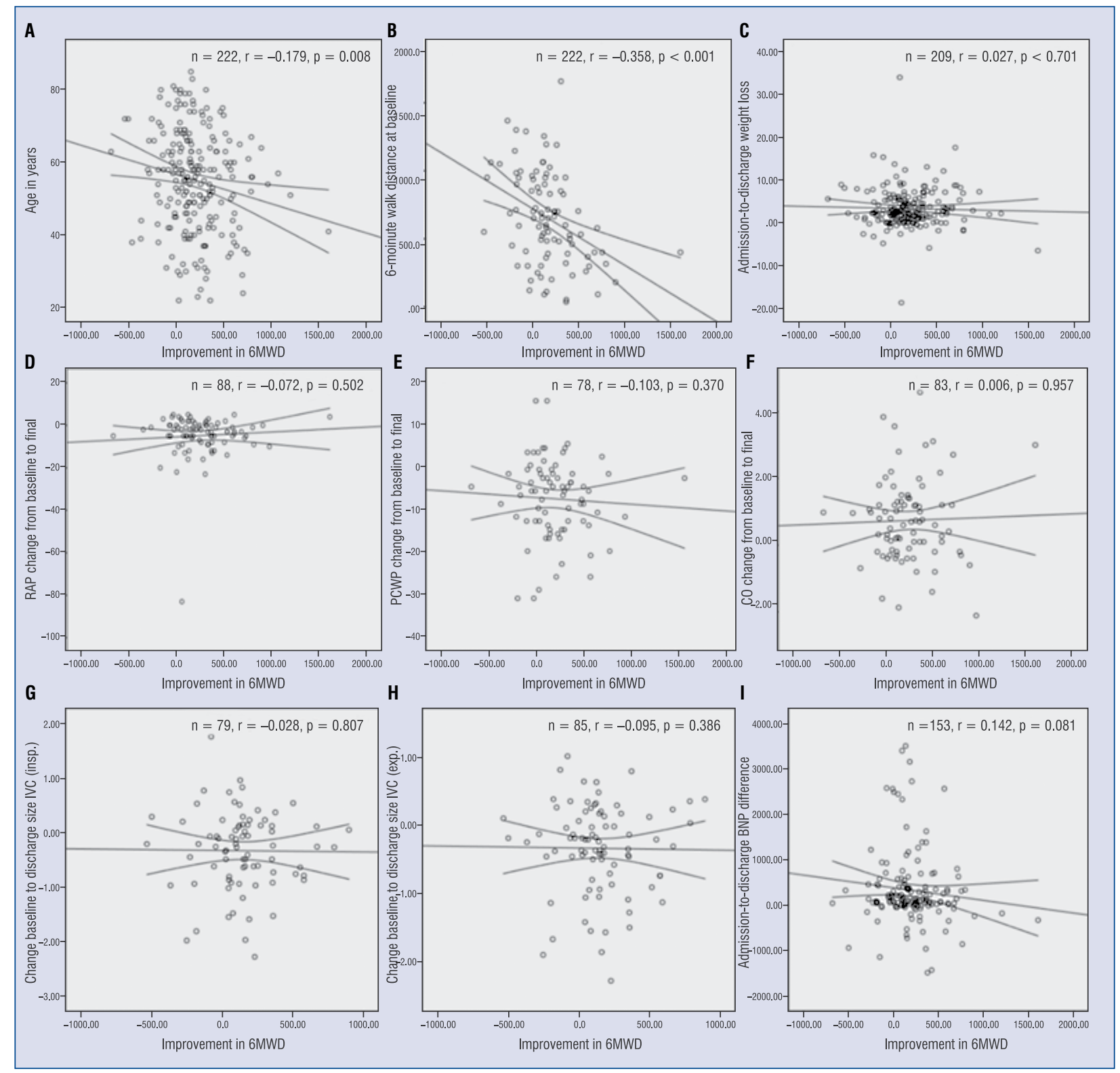

Figure 1. A-I. Scatter plots illustrating the association between various variables and improvement in 6-minute walk distance (6MWD) from admission to discharge in patients with acute heart failure enrolled in the ESCAPE trial; BNP — B-type natriretic peptide; CO — cardiac output; IVC — inferior vena cava; PCWP — pulmonary capillary wedge pressure; RAP — right atrial pressure.

ear regression analysis revealed that patients age (standardized $\beta=-0.239, \mathrm{p}=0.022$ ) and 6MWD on admission ( standardized $\beta=-0.529, \mathrm{p}<0.001$ ) were independent predictors of improvement in 6MWD after adjusting for EF (standardized $\beta=0.016, \mathrm{p}=0.869$ ), body mass index (standardized $\beta=0.146, \mathrm{p}=0.150$ ) and reduction in BNP from admission-to-discharge (standardized $\beta=0.061, \mathrm{p}=0.529$ ).

It was shown in this analysis that younger age and lower 6MWD on admission determined the improvement in walking distance from admission- -to-discharge in patients with acute $\mathrm{HF}$ and $\mathrm{EF}$ $\leq 30 \%$. These results remained unaltered on multivariate analysis. These finding are in-line with prior work by Passantino et al. [3] who found that age and 6MWD at baseline were inversely related to the increase in distance walked. We found no association between the degree of decongestion and the improvement in walking distance from admission to discharge. The degree of decongestion was thoroughly evaluated in our study through various clinical, laboratory, echocardiographic, and central hemodynamic variables of decongestion via the PAC. The present 
findings suggest that diuresis is not the main determinant for the improvement in the functional status of HF patients. Prior studies show that the 6MWD was sensitive to short-term changes in drug therapy [7]; for example, angiotensin converting enzyme inhibitors and beta-blockers were found to significantly improve submaximal exercise tolerance, as assessed by the 6MWD [8-10]. Unfortunately the lack of sufficient data on medication in the limited access dataset, prevented the assessment of the effect of various medications on the improvement in 6MWD.

There are several hypotheses to explain the lack of association between decongestion and improvement in walking distance. For example, a patient with predominantly left-sided failure will initially have symptoms of pulmonary congestion, but after small volume diuresis, symptoms will improve: in this scenario, one would expect a significant improvement in 6MWD despite only modest diuresis. Another scenario is a patient with hypertensive pulmonary edema who may experience relief of dyspnea with intravenous nitroglycerin causing venodilation without change in his volume status. Also, the functional capacity of HF patients is related not only to central "i.e. cardiac" factors, but also to "peripheral factor" like endothelial dysfunction, muscle performance, ventilatory inefficiency, which is less sensitive to improvements in the hemodynamic profile. Furthermore, the intensive diuretic therapy could lead to electrolytes abnormalities causing paradoxical worsening of fatigue and functional capacity. More importantly, the observation that patients with $>160$ feet $(49 \mathrm{~m})$ improvement in walking distance had lower admission 6MWD best exemplifies that the phenomenon of "regression to the mean" which describes the tendency of an extreme measurement on a first occasion to become less extreme when checked again — may have been responsible for masking the effect of decongestion on improvement in 6MWD. In this study, it was easier for a patient to have a larger improvement in $6 \mathrm{MWD}$ if the initial walking distance was too low. This statistical phenomenon happens in studies when repeated measurements are made for the same patient. Regression to the mean is concerning if the examined variable exhibits significant withinsubject variability on repeated measurements and this typically occurs if there is a high threshold for trial enrollment, making the entry measurements away from the patients' true mean. This represents a limitation to our study and therefore our results have to be interpreted with caution. Futher studies are needed to confirm our findings.

\section{Ackonowledgements}

The ESCAPE trial was conducted and supported by the NHLBI in collaboration with the ESCAPE Study Investigators. This article was prepared using a limited access dataset obtained from the NHLBI and does not necessarily reflect the opinions or views of the ESCAPE trial investigators or the NHLBI.

\section{Conflict of interest: None declared}

\section{References}

1. Fleg JL, Pina IL, Balady GJ, et al. Assessment of Functional Capacity in Clinical and Research Applications : An Advisory From the Committee on Exercise, Rehabilitation, and Prevention, Council on Clinical Cardiology, American Heart Association. Circulation. 2000; 102(13): 1591-1597, doi: 10.1161/01.cir.102.13.1591.

2. ATS Committee on Proficiency Standards for Clinical Pulmonary Function Laboratories. ATS statement: guidelines for the six-minute walk test. Am J Respir Crit Care Med. 2002; 166(1): 111-117, doi: 10.1164/ajrccm.166.1.at1102, indexed in Pubmed: 12091180.

3. Passantino A, Lagioia R, Mastropasqua F, et al. Short-term change in distance walked in $6 \mathrm{~min}$ is an indicator of outcome in patients with chronic heart failure in clinical practice. J Am Coll Cardiol. 2006; 48(1): 99-105, doi: 10.1016/j.jacc.2006.02.061, indexed in Pubmed: 16814655.

4. Abraham WT, Fisher WG, Smith AL, et al. MIRACLE Study Group. Multicenter InSync Randomized Clinical Evaluation. Cardiac resynchronization in chronic heart failure. N Engl J Med. 2002; 346(24): 1845-1853, doi: 10.1056/NEJMoa013168, indexed in Pubmed: 12063368.

5. Binanay C, Califf RM, Hasselblad V, et al. ESCAPE Investigators and ESCAPE Study Coordinators. Evaluation study of congestive heart failure and pulmonary artery catheterization effectiveness: the ESCAPE trial. JAMA. 2005; 294(13): 1625-1633, doi: 10.1001/jama.294.13.1625, indexed in Pubmed: 16204662.

6. Shah MR, Hasselblad V, Stinnett SS, et al. Hemodynamic profiles of advanced heart failure: association with clinical characteristics and long-term outcomes. J Card Fail. 2001; 7(2): 105-113, doi: 10.1054/jcaf.2001.24131, indexed in Pubmed: 11420761.

7. Gualeni A, D'Aloia A, Gentilini A, et al. Effects of maximally tolerated oral therapy on the six-minute walking test in patients with chronic congestive heart failure secondary to either ischemic or idiopathic dilated cardiomyopathy. Am J Cardiol. 1998; 81(11): 1370-1372, indexed in Pubmed: 9631981.

8. Hutcheon SD, Gillespie ND, Crombie IK, et al. Perindopril improves six minute walking distance in older patients with left ventricular systolic dysfunction: a randomised double blind placebo controlled trial. Heart. 2002; 88(4): 373-377, doi: 10.1136/ heart.88.4.373.

9. Krum H, Sackner-Bernstein JD, Goldsmith RL, et al. Doubleblind, placebo-controlled study of the long-term efficacy of carvedilol in patients with severe chronic heart failure. Circulation. 1995; 92(6): 1499-1506, indexed in Pubmed: 7664433.

10. Packer M, Colucci WS, Sackner-Bernstein JD, et al. Doubleblind, placebo-controlled study of the effects of carvedilol in patients with moderate to severe heart failure. The PRECISE Trial. Prospective Randomized Evaluation of Carvedilol on Symptoms and Exercise. Circulation. 1996; 94(11): 2793-2799, indexed in Pubmed: 8941104. 